\title{
PERFECCIONISMO, SINTOMATOLOGIA DEPRESSIVA E ACONTECIMENTOS DE VIDA NEGATIVOS NA IDEAC̣ÃO SUICIDA EM JOVENS-ADULTOS ${ }^{1}$

\author{
PERFECTIONISM, DEPRESSIVE SYMPTOMS AND NEGATIVE LIFE EVENTS \\ IN SUICIDAL IDEATION IN YOUNG ADULTS
}

\author{
Jenifer Mata², Ana Isabel Reis³, Marta Brás ${ }^{4}$ \\ PSIQUE • E-ISSN 2183-4806 • VOLUME XVII • ISSUE FASCÍCULO 1 \\ $1^{\text {ST }}$ JANUARY JANEIRO - 30 TH JUNE JUNHO 2021 •PP. 96-121 \\ DOI: https://doi.org/10.26619/2183-4806.XVII.NT.5 \\ Submited on 11.10.20 Submetido a 11.10.20 \\ Accept on 22.12.20 Aceite a 22.12.20
}

\begin{abstract}
Resumo
O suicídio resulta de um processo complexo, que normalmente se inicia com a ideação suicida. É uma das principais causas de mortes nos jovens-adultos, sendo um problema atual preocupante. O comportamento suicidário é influenciado por diversos fatores de risco, dos quais se salientam os acontecimentos de vida negativos, o perfeccionismo e a sintomatologia depressiva. Contudo, a relação que se estabelece entre estes fatores na explicação da ideação suicida é pouco estudada.

O presente estudo teve como principal objetivo analisar a influência dos acontecimentos de vida negativos, do perfeccionismo e da sintomatologia depressiva na ideação suicida, numa amostra de jovens-adultos de nacionalidade portuguesa.

A amostra foi composta por 224 jovens-adultos, com idades compreendidas entre os 18 e os 35 anos. Os participantes preencheram instrumentos que avaliavam: ideação suicida, acontecimentos de vida negativos, perfeccionismo e sintomatologia depressiva.

Os resultados indicam que a relação entre os acontecimentos de vida negativos e a ideação suicida é mediada parcialmente pela sintomatologia depressiva e que o perfeccionismo socialmente prescrito modera a relação entre a sintomatologia depressiva e a ideação suicida.

Conclui-se que, os jovens-adultos que experienciam mais acontecimentos de vida negativos poderão apresentar um risco acrescido de ideação suicida, que poderá ser intensificado pela sintomatologia depressiva. Quanto à relação entre a sintomatologia depressiva e a ideação suicida, esta é mais robusta nos jovens-adultos que possuem níveis mais elevados de perfeccionismo.

\footnotetext{
1 Este trabalho é financiado por fundos nacionais através da FCT - Fundação para a Ciência e a Tecnologia, I.P., no âmbito do projeto CIP - Ref ${ }^{\mathrm{a}}$ UIDB/PSI/04345/2020

2 Jenifer Daniela de Nóbrega da Mata, a57507@ualg.pt, Departamento de Psicologia e Ciências da Educação, Faculdade de Ciências Humanas e Sociais, Universidade do Algarve, Faro, Portugal Humanas e Sociais, Universidade do Algarve, Faro, Portugal

4 Autor de correspondência: Marta Sofia Ventosa Brás, mbras@ualg.pt, Centro de Investigação em Psicologia (CIP) / Departamento de Psicologia e Ciências da Educação, Faculdade de Ciências Humanas e Sociais, Universidade do Algarve Faro, Portugal
}

3 Ana Isabel Oliveira dos Reis, a57495@ualg.pt, Departamento de Psicologia e Ciências da Educação, Faculdade de Ciências
\end{abstract}


Torna-se, assim, relevante a avaliação destes fatores de risco, de modo a prevenir os comportamentos suicidários e desenvolver uma intervenção mais adequada.

Palavras-chave: acontecimentos de vida negativos, depressão, ideação suicida, jovens-adultos, perfeccionismo

\begin{abstract}
Suicide is the result of a complex process, which usually begins with suicidal ideation. It is one of the main causes of death in young adults and is a current worrying problem. Suicidal behavior is influenced by several risk factors, among which negative life events, perfectionism and depressive symptomatology stand out. However, the relationship established between these factors in explaining suicidal ideation is poorly studied.

The main objective of this study was to analyze the influence of negative life events, perfectionism and depressive symptomatology on suicidal ideation, in a sample of young adults of portuguese nationality.

The sample consisted of 224 young-adults, aged between 18 and 35 years. Participants filled out instruments that assessed: suicidal ideation, negative life events, perfectionism and depressive symptomatology.

The results indicate that the relationship between negative life events and suicidal ideation is partially mediated by depressive symptomatology and that socially prescribed perfectionism moderates the relationship between depressive symptomatology and suicidal ideation.

It is concluded that young adults who experience more negative life events may present an increased risk of suicidal ideation, which may be intensified by depressive symptomatology. As for the relationship between depressive symptomatology and suicidal ideation, this is more robust in young adults who have higher levels of perfectionism. It is, therefore, relevant to assess these risk factors, in order to prevent suicidal behavior and carry out a more appropriate intervention.
\end{abstract}

Keywords: depression, negative life events, perfectionism, suicidal ideation, young adults

\title{
1. Introdução
}

O suicídio é um fenómeno complexo, para o qual contribuem diversos fatores: biológicos, antropológicos, filosóficos, sociais e psicológicos (Direção-Geral da Saúde [DGS], 2013). No âmbito da área científica da psicologia, o estudo do comportamento suicidário é um tema atual e pertinente, tanto do ponto de vista empírico, como do ponto de vista social e da prática clínica. Assim, o objetivo geral do presente estudo consiste em analisar a influência dos acontecimentos de vida negativos, das dimensões do perfeccionismo e da sintomatologia depressiva na ideação suicida. 


\subsection{Suicídio}

Os atos suicidas constituem um grave problema de saúde pública a nível mundial. A Organização Mundial de Saúde (OMS) estima que mais de 700 mil pessoas morrem por suicídio por ano, o que corresponde a uma pessoa a cada 40 segundos. Em 2019, o suicídio foi responsável por 1.3\% das mortes auto-provocadas, tornando-se a 17. ${ }^{a}$ causa de morte. Ainda, mundialmente, a população jovem-adulta evidencia resultados alarmantes, sendo o suicídio a quarta principal causa de morte para as idades compreendidas entre os 15 e os 29 anos (OMS, 2021).

No ano 2019, o continente europeu apresentou uma taxa de suicídio (10.5 por 100 mil habitantes) superior à da média global (9.0 por 100 mil habitantes), representando o segundo continente com maior incidência de comportamentos suicidários (OMS, 2021).

Em Portugal, desde que existem registos oficiais de taxas de suicídio, verifica-se uma maior prevalência na região sul. Os resultados apontam também o suicídio como uma das principais causas de morte em jovens portugueses, com idades compreendidas entre os 15 e os 24 anos (DGS, 2013).

De acordo com o Instituto Nacional de Estatística (INE), a nível nacional, no ano 2019, a taxa de mortalidade por lesões auto-provocadas intencionalmente (suicídio) foi de $9.5 \%$ por 100 mil habitantes, apresentando o sexo feminino valores inferiores $(4.4 \%)$ ao sexo masculino (15.2\%) (INE, 2021). Embora a taxa de mortalidade por suicídio seja superior no sexo masculino, sabe-se que a ideação suicida e as tentativas de suicídio são mais prevalentes no sexo feminino, assim como outros indicadores de menor qualidade de saúde mental (elevados níveis de psicopatologia, especificamente de stresse, ansiedade e depressão) (Fonte et al., 2017).

\subsection{Processo suicidário}

O processo suicidário pode evoluir ao longo de quatro fenómenos essenciais: a ideação suicida, os comportamentos autolesivos, a tentativa de suicídio e o suicídio consumado, sendo que os dois últimos integram os atos suicidas (DGS, 2013).

A ideação suicida remete para os pensamentos e cognições sobre pôr fim à própria vida, podendo apresentar-se na forma de desejos e/ou plano para cometer o suicídio. Adicionalmente, é pertinente realçar que a ideação suicida é normalmente o marco primário do processo, precedendo os comportamentos autolesivos e os atos suicidas e, por conseguinte, é um forte preditor para a ocorrência de comportamentos suicidários, o que significa que, quanto maior for a ideação suicida, maior será o risco de o indivíduo cometer um comportamento suicida (DGS, 2013). Botega et al. (2005) revelam que a presença de pensamentos suicidas representa um elevado risco para a concretização de uma tentativa de suicídio, existindo empiricamente uma forte relação entre as duas variáveis.

Os comportamentos autolesivos são comportamentos sem intencionalidade suicida, no entanto, envolvem atos propositados, realizados contra o próprio indivíduo. A título de exemplo, cortar-se ou saltar de um local relativamente elevado; ingerir fármacos em doses superiores ao prescrito (DGS, 2013).

Relativamente aos atos suicidas, a tentativa de suicídio é o ato provocado por um indivíduo que tenciona pôr fim à sua vida, porém, por motivos alheios à sua vontade, acaba por não ser fatal. O suicídio consumado consiste no ato de morte auto-provocada, cujo indivíduo continha a intencionalidade de pôr termo à sua vida (DGS, 2013). 
Tendo em consideração o anteriormente aludido, torna-se fundamental estudar o início do processo suicidário (ideação suicida), de maneira a prevenir potenciais atos suicidas, como também, adquirir conhecimento acerca dos principais fatores de risco que podem desencadear algum grau de vulnerabilidade para a ideação suicida.

\subsection{Fatores de risco}

A identificação dos fatores de risco é fundamental para a prevenção do suicídio, proporcionando a compreensão do fenómeno e o desenvolvimento de intervenções adequadas (DGS, 2013).

O perfeccionismo é um dos fatores de risco que tem sido consistentemente relacionado ao comportamento suicidário (e.g., Hewitt E Flett, 1991; O’Connor, 2007; Roxboroug et al., 2012; Shahnaz et al., 2018; Smith et al., 2017). O perfeccionismo é um traço de personalidade multidimensional (características intrapessoais e interpessoais), definido pelo estabelecimento de padrões de desempenho excessivamente elevados, acompanhado de uma autoavaliação extremamente autocrítica (Frost et al., 1990).

Os acontecimentos de vida negativos também têm vindo a ser mencionados como um fator influente no processo suicidário (e.g., Liu \& Miller, 2014; Low et al., 2017; Serafini et al., 2015; Ystgaard et al., 2004). Os acontecimentos de vida negativos são definidos como eventos que ocorrem antes dos 18 anos de idade e que são suscetíveis de possuir um impacto negativo na vida do indivíduo. Estes acontecimentos consistem no historial psicopatológico da família, na ocorrência de maus-tratos na infância, na instabilidade familiar, na presença de um ambiente familiar empobrecido e no desenvolvimento de relações insatisfatórias com os pares (Yang \& Clum, 1996).

A perturbação mental constitui-se também um fator de risco significativo, atendendo que existem estudos que demonstram que cerca de $90 \%$ das pessoas que se suicidaram sofriam de uma perturbação mental (DGS, 2013). A literatura apresenta a sintomatologia depressiva como um fator de risco para o comportamento suicida (e.g., Garlow et al., 2008; May \& Klonsk, 2016). A depressão é definida como uma perturbação mental caracterizada pela presença de humor triste, vazio ou irritável, juntamente com alterações somáticas e cognitivas que afetam consideravelmente a capacidade do funcionamento do individuo (American Psychiatric Association [APA], 2014).

Enfatiza-se que na presença de um aglomerado de fatores negativos, existe uma maior probabilidade de ocorrência de comportamentos autolesivos e atos suicidas. Porém, não é um único fator de risco que determina o ato suicida. Nem todos os fatores são significativos no que diz respeito à prevenção, sendo pertinente que sejam analisados em conjunto (DGS, 2013).

\subsection{Modelos explicativos}

\subsubsection{Modelo Etiológico do Comportamento Suicida (Yang \& Clum, 1996)}

Na década de 90, surgem os primeiros modelos psicológicos explicativos dos comportamentos suicidários. O Modelo Etiológico do Comportamento Suicida desenvolvido por Yang e Clum (1996) postula que os acontecimentos de vida negativos, sobretudo maus-tratos experienciados na infância e adolescência, podem conduzir a um ato suicidário, estando mediados por fatores cognitivos, tais como, a desesperança, o locus de controlo, os sentimentos de dependência, 
a autoestima e a capacidade de resolução de problemas. Os autores salientam ainda que, um ambiente familiar instável, aumenta a probabilidade de desenvolver este tipo de comportamento.

Os acontecimentos de vida negativos podem influenciar de forma direta e indireta os comportamentos suicidas. Diretamente, como um evento stressante e, indiretamente, afetando os fatores cognitivos que, por sua vez, conduzem ao ato suicida (Yang \& Clum, 1996).

\subsubsection{Modelo Cognitivo do Suicídio (Wenzel \& Beck, 2008)}

Alguns anos mais tarde, Wenzel e Beck (2008) desenvolveram o Modelo Cognitivo do Suicídio que integra três construtos que sustentam os comportamentos suicidários, nomeadamente, fatores de vulnerabilidade disposicional, processos cognitivos associados às perturbações psiquiátricas e processos cognitivos relacionados com o comportamento suicidário.

O modelo inclui o perfeccionismo como um traço de personalidade de risco para a ocorrência de um ato suicidário, sendo considerado um fator de vulnerabilidade. Wenzel e Beck (2008) defendem ainda que tais fatores, associados a acontecimentos de vida negativos, podem tornar o sujeito mais vulnerável a esquemas cognitivos disfuncionais, característicos de perturbações psicológicas, como é o caso da perturbação depressiva. Deste modo, a depressão pode remeter para processos cognitivos alusivos à ideação suicida e, consequentemente, despoletar a consumação do ato suicida.

\subsubsection{Modelo de Desconexão Social do Perfeccionismo (PSDM) (Hewitt et al., 2006; Hewitt et al., 2017)}

O Modelo de Desconexão Social do Perfeccionismo (PSDM) pretende averiguar a relação entre o perfeccionismo e a psicopatologia e foi desenvolvido por Hewitt et al. (Hewitt et al., 2006; Hewitt et al., 2017).

O Modelo de Desconexão Social do Perfeccionismo sugere que o perfeccionismo socialmente prescrito $^{5}$ desencadeia problemas interpessoais, resultantes em maiores niveis de hostilidade e sensibilidade excessiva à crítica e rejeição. Estes problemas, por sua vez, emergem em sentimentos de distanciamento dos outros (desconexão social subjetiva), dificuldades nos relacionamentos interpessoais (desconexão social objetiva) e, consequentemente, isolamento social (Hewitt et al., 2006).

O modelo teoriza que o perfeccionismo socialmente prescrito conduz à ideação suicida, por meio de problemas interpessoais e desconexão social. O que significa que são as consequências interpessoais do perfeccionismo, como o isolamento, a solidão e o sentimento de falta de pertença, que podem contribuir para o ato suicida (Hewitt et al., 2006).

Hewitt et al. (2017) estenderam o Modelo da Desconexão Social do Perfeccionismo anteriormente referido, passando a incutir a variável acontecimentos de vida negativos. Os autores defendem que as adversidades ou maus-tratos na infância são um importante fator de vulnerabilidade para o desenvolvimento de traços e comportamentos perfeccionistas. O perfeccionismo passa, assim, a desenvolver-se parcialmente como consequência dos comportamentos parentais adversos e experiências traumáticas na infância. Enaltece-se que os acontecimentos de vida

\footnotetext{
5 O perfeccionismo socialmente prescrito (PSP) é uma dimensão interpessoal do perfeccionismo que envolve a crença de que os outros possuem padrões e expetativas irrealistas para si próprio (Hewitt \& Flett, 1991).
} 
negativos vivenciados pelos indivíduos com perfeccionismo colocam-nos vulneráveis a desenvolver ideação suicida.

Considerando os modelos supramencionados, identifica-se como principais fatores de risco o perfeccionismo, os acontecimentos de vida negativos e a depressão.

\subsection{O contributo do perfeccionismo para a ideação suicida}

Hewitt e Flett (1991) conceituaram o perfeccionismo em três dimensões, mais concretamente, Perfeccionismo Auto-Orientado (PAO), Perfeccionismo Socialmente Prescrito (PSP) e Perfeccionismo Orientado para os Outros (POO). O PAO refere-se à tendência para estabelecer padrões de desempenho excessivamente elevados, para si próprio, e praticamente inexequíveis. O PSP envolve a crença de que os outros possuem padrões e expetativas irrealistas para si próprio e acredita que se não corresponder a tais expetativas, poderá não ser aceite. E, por último, o POO abrange crenças e expetativas sobre as capacidades dos outros, como colocar padrões irrealistas de que os outros são perfeitos. Para além disso, os autores sustentam que a excessiva necessidade de ser perfeito perante os outros, pode gerar desconexão social, alienação e solidão, culminando na ideação suicida e tentativas de suicídio.

Do ponto de vista empírico, as dimensões que têm demonstrado melhor evidência, quando associadas aos comportamentos suicidários, são o perfeccionismo auto-orientado e o perfeccionismo socialmente prescrito. O perfeccionismo socialmente prescrito parece favorecer o aumento da ideação suicida e das tentativas de suicídio, enquanto o perfeccionismo auto-orientado associa-se apenas à ideação suicida (Smith et al., 2017). Os autores defendem ainda que os indivíduos que apresentam traços perfeccionistas podem possuir pensamentos e comportamentos com consequências suicidárias. Robinson et al. (2021) acrescentam que as três dimensões do perfeccionismo foram associadas positivamente à ideação suicida. Adicionalmente, o perfeccionismo socialmente prescrito e o perfeccionismo auto-orientado podem estar associados aos comportamentos suicidários nos jovens (Roxboroug et al., 2012).

Os indivíduos perfeccionistas tendem a definir padrões irrealistas para si próprios, que por vezes, são incapazes de atingir. $O$ fracasso resultante dessas expetativas pode originar sentimentos de ineficácia ou incompetência, levando a que o individuo se percecione como um fardo para os outros. Assim, Ramussem et al. (2012) evidenciam que a perceção de ser um fardo para os outros e o perfeccionismo patológico encontram-se associados à ideação suicida.

Shahnaz et al. (2018) salientam que o perfeccionismo pode ser um fator de risco para a ideação suicida, como também, defendem que a relação existente entre o perfeccionismo e a tentativa de suicídio pode ser influenciada pela ideação suicida.

Mais recentemente, Jonge-Heesen et al. (2021) também vão ao encontro com os estudos precedentes, defendendo que elevados níveis de perfeccionismo, estão relacionados com um aumento de tendência suicida. Brennan-Wydra et al. (2021) enaltecem que existe uma associação positiva e significativa entre o perfeccionismo desadaptativo e a ideação suicida.

A revisão da literatura aponta assim para o perfeccionismo como um fator relevante na explicação do suicídio, sendo este um traço que tem sido relacionado de modo consistente ao comportamento suicidário em populações clínicas e não-clínicas (O’Connor, 2007).

Dentro da mesma perspetiva, Johnson et al. (2011) efetuaram uma meta-análise com 77 estudos, com a finalidade de investigar a existência de moderadores psicológicos de risco suicidário. 
Os resultados apontam que os níveis elevados de perfeccionismo contribuem para amplificar outros fatores de risco que estão associados aos comportamentos suicidários. Sommerfeld e Malek (2019) concluíram que existe um papel moderador das dimensões do perfeccionismo, mais precisamente, do perfeccionismo auto-orientado e do perfeccionismo socialmente prescrito na relação entre os fatores de desconexão social e a ideação suicida. Ainda assim, apesar de estar clarificado na literatura que o perfeccionismo é um fator de vulnerabilidade para a ideação suicida, ainda existe pouca investigação sobre quais são os moderadores pelos quais as variáveis se encontram interligadas (Bender, 2020; Zeifman et al., 2020).

\subsection{A vivência de acontecimentos de vida negativos por indivíduos perfeccionistas e as suas consequências na ideação suicida}

A vivência de acontecimentos de vida negativos parece ser uma variável comum à maioria dos indivíduos que comete atos suicidas (Ystgaard et al., 2004). Liu e Miller (2014), através de uma revisão sistemática com 95 estudos, reforçam que existe uma associação entre os acontecimentos de vida negativos e os diferentes comportamentos suicidários.

Um ano mais tarde, Serafini et al. (2015), mediante uma revisão sistemática com 28 estudos, chegam à mesma conclusão, admitindo que a maioria dos estudos relata uma associação robusta entre os acontecimentos de vida negativos e os processos suicidários, sobretudo, com a ideação suicida e as tentativas de suicídio. Os autores acrescentam ainda que o número e o tipo de adversidades vivenciadas são relevantes para o desenvolvimento do comportamento suicida nos jovens.

Low et al. (2017) indicam que a ocorrência de abuso físico na infância se encontra significativamente associada a uma maior ideação suicida nos jovens universitários.

Liu et al. (2017), através de uma meta-análise, frisam que os maus-tratos na infância aumentam o risco de comportamento suicida, contudo, ao contrário do que já foi exposto anteriormente, revelam que os acontecimentos de vida negativos não influenciam a ideação suicida, apenas as tentativas de suicídio.

Considerando as diferentes componentes traumáticas que estão subjacentes aos acontecimentos de vida negativos, nomeadamente o abuso emocional, a negligência emocional, o abuso sexual, o abuso físico e a negligência física (Dias et al., 2013), destaca-se que a negligência e o abuso emocional encontram-se significativamente associados ao risco suicidário (Falgares et al., 2018). Wang et al. (2019) postularam que a exposição de uma criança a situações de isolamento/ rejeição dos pares, negligência emocional e baixo nível socioeconómico aumentam significativamente o risco de ideação suicida. Os autores destacam também que quanto maior a vivência de acontecimentos de vida negativos, maior é a tendência para pensamentos suicidas.

Os abusos infantis, quer sejam físicos, emocionais ou sexuais, são preditores do perfeccionismo auto-orientado e do perfeccionismo socialmente prescrito (Chen et al., 2019). O que vai ao encontro com o Modelo da Desconexão Social do Perfeccionismo (Hewitt et al., 2017) anteriormente referido, uma vez que a ocorrência de acontecimentos de vida negativos é um fator de vulnerabilidade para o desenvolvimento de traços perfeccionistas. O modelo evidencia ainda que os indivíduos perfeccionistas com vivências de adversidades ou maus-tratos na infância são mais vulneráveis a desenvolver ideação suicida. 


\subsection{O papel da depressão na relação entre os acontecimentos de vida negativos, perfeccio- nismo e ideação suicida}

A sintomatologia depressiva detém uma associação proeminente com a ideação suicida, o que explica a ideação suicida nos jovens-adultos que apresentam sintomas depressivos graves. Em contrapartida, os indivíduos que não apresentam ideação suicida manifestam sintomas depressivos significativamente mais baixos (Garlow et al., 2008). May e Klonsky (2016) concluíram que a depressão é mais frequente em indivíduos que tentam o suicídio do que naqueles que possuem apenas ideação suicida. Apesar disso, os autores corroboram com o estudo anterior, afirmando que os diagnósticos depressivos são mais frequentes em indivíduos com ideação suicida, quando comparados com indivíduos sem qualquer fenómeno do processo suicidário, sugerindo que os sintomas depressivos tornam os indivíduos mais vulneráveis ao comportamento suicidário.

Considerando que os acontecimentos de vida negativos e a depressão associam-se significativamente com a ideação suicida, torna-se fundamental investigar se existe uma relação entre estes dois fatores de risco, de forma a percecionar se ambos podem influenciar-se e, consequentemente, desencadear pensamentos e cognições suicidas.

Num estudo com 225 mulheres portuguesas, Pinto et al. (2015) realçaram que a exposição a experiências adversas na infância está associada, e é preditora de sintomatologia depressiva e de tentativas de suicídio. Adicionalmente, a existência de acontecimentos de vida negativos aumenta significativamente o surgimento de sintomatologia depressiva e comportamentos suicidas (Chang et al., 2016).

De acordo com o exposto na literatura, os acontecimentos de vida negativos são preditores da sintomatologia depressiva (Pinto et al., 2015). Portanto, realça-se, a pertinência de estudar o modo como os acontecimentos de vida negativos interagem com a sintomatologia depressiva no desenvolvimento da ideação suicida.

Em 2016, Sobrinho e Campos estudaram a relação que existe entre os acontecimentos de vida negativos e o risco de suicídio e a maneira como esta é influenciada pela depressão. Os resultados obtidos evidenciam que a sintomatologia depressiva medeia a relação entre a frequência e a intensidade de acontecimentos de vida negativos e o risco de suicídio, o que explica que um jovem que vivencie acontecimentos de vida negativos se encontre mais vulnerável a desenvolver sintomatologia depressiva. Por conseguinte, a depressão acaba por provocar maior sofrimento psicológico, aumentando o risco de o jovem desenvolver um comportamento suicida.

Embora haja evidência do efeito da depressão na relação entre os acontecimentos de vida negativos e o risco de suicídio, ainda existe uma lacuna quanto ao papel mediador da sintomatologia depressiva na relação entre os acontecimentos de vida negativos e a ideação suicida.

Além dos acontecimentos de vida negativos, é também relevante averiguar a relação entre o perfeccionismo e a depressão. Besser et al. (2010) enfatizam que os indivíduos com altos níveis de perfeccionismo socialmente prescrito e perfeccionismo auto-orientado são propensos a desenvolver sintomatologia depressiva. Alguns anos mais tarde, Kiani e Khodabakhsh (2014) voltam a frisar a importância do perfeccionismo na predição da sintomatologia depressiva. O perfeccionismo socialmente prescrito confere vulnerabilidade aos indivíduos para desenvolverem sintomatologia depressiva (Smith et al., 2018).

Hewitt et al. (2014) num estudo sobre as dimensões do perfeccionismo, stresse, desesperança e ideação suicida, com uma amostra de 55 pacientes psiquiátricos adolescentes diagnosticados com depressão, realçam que o perfeccionismo socialmente prescrito está associado ao risco 
global de suicídio, como também, se correlaciona significativamente aos acontecimentos de vida negativos e à depressão. Por sua vez, os resultados do estudo indicam que a ideação suicida foi significativamente relacionada com o stresse, a depressão e a desesperança. Adicionalmente, o perfeccionismo socialmente prescrito parece ser particularmente relevante na previsão do potencial suicida em adolescentes deprimidos.

Considerando a revisão da literatura exposta, constata-se que os fatores de risco em estudo, mais precisamente, o perfeccionismo, os acontecimentos de vida negativos e a depressão possuem uma robusta associação com a ideação suicida. Contudo, é importante a realização de um estudo que contemple todas estas variáveis e que demonstre de que maneira estas podem ou não estar envolvidas na génese do suicídio. Pretende-se, assim, investigar se os acontecimentos de vida negativos, perfeccionismo, depressão e ideação suicida, revelam associações significativas entre si e se influenciam o desenvolvimento de ideação suicida de forma direta ou mediada. Desta forma, será possível contribuir para uma melhor compreensão dos fatores de risco do processo suicidário nos jovens-adultos.

\section{Objetivos}

O objetivo geral do presente estudo consiste em analisar a influência dos acontecimentos de vida negativos, das dimensões do perfeccionismo e da sintomatologia depressiva na ideação suicida, numa amostra de jovens-adultos de nacionalidade portuguesa. De modo a concretizar o objetivo geral, foram delineados os seguintes objetivos específicos:

Explorar os níveis de perfeccionismo, sintomatologia depressiva, ideação suicida e a vivência de acontecimentos negativos nos jovens-adultos estudados;

Analisar o valor preditor dos fatores de risco na explicação da ideação suicida;

Explorar o efeito mediador da sintomatologia depressiva na relação entre os acontecimentos de vida negativos e a ideação suicida;

Averiguar o papel moderador das dimensões do perfeccionismo na relação entre a sintomatologia depressiva e a ideação suicida.

\section{Método}

\subsection{Desenho do estudo}

O estudo apresenta um design descritivo, correlacional e transversal.

\subsection{Amostra}

A amostra do presente estudo é composta por 224 jovens-adultos de nacionalidade portuguesa, dos quais 166 são do sexo feminino (74.1\%) e 58 do sexo masculino (25.9\%), com idades compreendidas entre os 18 e os 35 anos $(M=22.71$; $D P=3.43)$. A maioria dos participantes são solteiros (92.9\%), estudantes (62.9\%), com habilitações literárias ao nível do ensino superior (62.9\%) 
e maioritariamente residem em Portugal Continental, sendo que 7.1\% habita na Região Autónoma da Madeira.

A nível do historial psicopatológico, 85 (37.9\%) jovens-adultos revelaram que já foram acompanhados por um profissional de saúde mental e 42 (18.8\%) referem já ter tido pelo menos um problema psicológico diagnosticado. Verificou-se que praticamente metade da amostra (46.4\%) já sentiu que não valia a pena viver, sendo que 28 (12.5\%) participantes já cometeram atos autolesivos (e.g., cortes) e 15 (6.7\%) tentaram pôr fim à sua própria vida.

\subsection{Instrumentos}

\subsubsection{Questionário Sociodemográfico e Clínico}

O Questionário Sociodemográfico e Clínico foi desenvolvido para a investigação em causa, permitindo recolher a informação acerca das variáveis sociodemográficas, tais como a idade, o género, a nacionalidade, o distrito de residência, o estado civil e as habilitações literárias. Ademais, possibilitou conhecer o historial clínico e psicopatológico do indivíduo.

\subsubsection{Escala Multidimensional de Perfeccionismo (HMPS)}

A Escala Multidimensional de Perfeccionismo, originalmente designada de Multidimensional Perfectionism Scale (Hewitt \& Flett, 1991), foi adaptada para a versão portuguesa por Soares et al. (2003). Detém como principal finalidade analisar as três dimensões do perfeccionismo: PAO, PSP e POO.

A HMPS é constituída por 45 itens, avaliados numa escala de Likert de 7 pontos, de 1 (Discordo completamente) a 7 (Concordo completamente). Os itens distribuem-se por três subescalas: perfeccionismo auto-orientado (18 itens) (e.g., "Preocupo-me em ter um resultado perfeito em tudo"), perfeccionismo socialmente prescrito (14 itens) (e.g., "Sinto que as outras pessoas exigem demais de mim") e perfeccionismo orientado para os outros (8 itens) (e.g., "É-me indiferente que um bom amigo não tente fazer o seu melhor") (Soares et al., 2003).

Relativamente à pontuação, cada item é cotado numa escala de 1 a 7, porém, 19 itens são cotados em sentido inverso. A pontuação total é alcançada através da soma das pontuações de cada item. Quanto mais elevada for a pontuação, mais elevados são os níveis de perfeccionismo (Soares et al., 2003).

A versão original da escala demonstra qualidades psicométricas satisfatórias, assim como, a versão portuguesa que evidencia uma consistência interna adequada, tanto na escala total $(=.89)$, como nas subescalas que a constituem: PAO (= .89), PSP $(=.83)$ e PAO $(=.69)$ (Soares et al., 2003).

No presente estudo foram utilizadas apenas duas das três subescalas, nomeadamente as que avaliam o perfeccionismo auto-orientado e o perfeccionismo socialmente prescrito. Optou-se por esta restrição, devido as dimensões selecionadas apresentarem maior evidência empírica, quando relacionadas com os comportamentos suicidários. Deste modo, é pertinente salientar o que cada uma averigua, o PAO avalia o estabelecimento de padrões excessivamente elevados para o próprio indivíduo e o PSP mede a perceção de que os outros definem e impõem padrões e expetativas irrealistas dirigidas ao próprio indivíduo (Hewitt \& Flett, 1991). 
Relativamente à fiabilidade, as subescalas utilizadas no presente estudo revelaram uma boa consistência interna: PAO ( = .91); PSP ( = .87).

\subsubsection{Inventário de Ideação Suicida Positiva e Negativa (PANSI)}

O Inventário de Ideação Suicida Positiva e Negativa (Positive and Negative Suicide Ideation Inventory), desenvolvido por Osman et al. (1998) e está em adaptação para a população portuguesa por Brás et al. e tem como objetivo avaliar os pensamentos positivos e negativos relacionados com a ideação suicida nas duas últimas semanas.

O PANSI é um instrumento de autorresposta, composto por 14 itens, expostos numa escala de Likert de cinco pontos, mais precisamente, de 1 (Nunca) a 5 (Muito frequentemente). Divide-se em dois fatores: ideação negativa (e.g., "Sentiu desesperança face ao futuro e ponderou terminar com a sua própria vida?”) e ideação positiva (e.g., "Sentiu-se confiante na sua capacidade de lidar com a maioria dos problemas da sua vida?"), sendo o primeiro composto por oito itens e, o segundo por seis itens (Osman et al., 1998).

No que diz respeito à pontuação, o PANSI não permite o cálculo de um score único total. Ainda assim, é possível obter o score de cada fator através da média aritmética dos itens (Muehlenkamp et al., 2005). Uma pontuação elevada de ideação negativa sugere uma maior frequência de ideação suicida, enquanto uma classificação elevada na ideação positiva remete para uma menor frequência de ideação suicida (Osman et al., 1998).

No que concerne à consistência interna, verifica-se que, no estudo original, foram obtidos valores satisfatórios, tanto na subescala ideação negativa $(=.91)$, como na ideação positiva $(=.80)$ (Osman et al., 1998).

Neste estudo utilizou-se a versão em processo de adaptação à população portuguesa, tendo sido obtido valores adequados de consistência interna em ambas as subescalas: ideação negativa $(=.96)$ e ideação positiva $(=.80)$.

\subsubsection{Escala de Ansiedade, Depressão e Stresse (EADS-21)}

A Escala de Ansiedade, Depressão e Stresse é a versão portuguesa da Depression Anxiety Stress Scale de Lovibond e Lovibond (1995). Foi adaptada para português por Pais-Ribeiro et al. (2004). Tem como principal objetivo avaliar a sintomatologia associada aos estados de ansiedade, depressão e stresse.

O instrumento é composto por 21 itens, agrupados em três subescalas: ansiedade (e.g., "Senti dificuldades em respirar"), depressão (e.g., "Senti que não tinha muito valor como pessoa") e stresse (e.g., "Senti que estava a utilizar muita energia nervosa"). Cada subescala é constituída por 7 itens, com 4 hipóteses de resposta: de 0 (Não se aplicou nada a mim) a 3 (Aplicou-se a mim a maior parte das vezes). Os itens remetem para sintomas afetivos negativos, onde os sujeitos avaliam a extensão em que experimentaram cada sintoma durante a última semana (Pais-Ribeiro et al., 2004).

A escala proporciona três pontuações, uma para cada dimensão, que são estipuladas pela soma dos resultados dos 7 itens correspondentes, podendo variar entre um mínimo de 0 e um máximo de 21 pontos. As classificações mais elevadas de cada subescala correspondem a estados afetivos mais negativos (Pais-Ribeiro et al., 2004).

Considerando os objetivos do presente estudo, apenas será analisada a subescala da depressão. Esta inclui itens direcionados à disforia (e.g., "Senti-me desanimado e melancólico”), desânimo 
(e.g., "Senti que não tinha nada a esperar do futuro"), desvalorização da vida (e.g., "Senti que a vida não tinha sentido"), autodepreciação (e.g., "Senti que não tinha muito valor como pessoa"), falta de interesse ou de envolvimento (e.g., "Não fui capaz de ter entusiasmo por nada"), anedonia (e.g., "Não consegui sentir nenhum sentimento positivo") e inércia (e.g., "Tive dificuldade em tomar iniciativa para fazer coisas") (Pais-Ribeiro et al., 2004).

Relativamente à fiabilidade, o instrumento revela valores satisfatórios de consistência interna nas suas subescalas: ansiedade ( = .74), depressão ( = .85) e stresse (= .81) (Pais-Ribeiro et al., 2004).

Na presente investigação obteve-se uma consistência interna muito boa, mais especificamente, na escala total $(=.96)$ e na subescala depressão $(=.93)$.

\subsubsection{Questionário de Trauma de Infância - Versão Breve (CTQ-SF)}

O Questionário de Trauma de Infância - Versão Breve é a versão portuguesa (Dias et al., 2013) do Childhood Trauma Questionnaire - Short Form (Bernstein et al., 2003). É um instrumento de autorresposta que permite avaliar a existência de eventos traumáticos na infância.

O questionário é composto por 28 itens, apresentados numa escala de Likert de 1 (Nunca) a 5 (Sempre). Analisa cinco componentes traumáticas, nomeadamente, o abuso emocional (e.g., "Pessoas da minha infância diziam coisas que me magoaram ou ofenderam"), o abuso físico ("Na minha infância batiam-me tanto que me deixavam pisado ou com nódoas negras no corpo"), o abuso sexual (e.g., "Tentaram forçar-me a fazer ou a assistir a algo sexual"), a negligência emocional (e.g., "As pessoas da minha família cuidavam uma das outras") e a negligência física (e.g., “Tinha que usar roupas sujas"). Cada subescala é constituída por 5 itens (Dias et al., 2013).

Quanto à cotação, os itens são pontuados de 1 a 5, de acordo com a frequência em que ocorreram, à exceção dos itens que descrevem uma infância agradável (2, 5, 7, 13, 19, 26 e 28), que são cotados de modo inverso. A classificação final é obtida através da soma das cotações de cada uma das questões, sendo que valores mais elevados indicam uma maior e mais grave exposição a traumas na infância (Dias et al., 2013).

A nivel de fiabilidade, a versão portuguesa apresenta resultados adequados na escala total $(=.84)$ e nas suas subescalas: abuso emocional $(=.71)$, abuso físico $(=.77)$, abuso sexual $(=.71)$ e negligência emocional ( = .79), à exceção da subescala negligência física ( = .47) que apresenta uma consistência interna baixa (Dias et al., 2013).

No presente estudo, os valores da consistência interna mostraram-se satisfatórios, tanto para a escala total $(=.82)$, como para as respetivas subescalas, abuso emocional $(=.87)$, negligência emocional ( = .89), abuso sexual ( = .92) e abuso físico $(=.81)$. Por outro lado, a subescala negligência física $(=.58)$ apresenta uma consistência interna baixa, à semelhança dos valores obtidos no estudo da versão portuguesa do instrumento.

\subsection{Procedimentos}

\subsubsection{Procedimento de recolha de dados}

A aplicação do protocolo realizou-se online, com recurso à plataforma digital Google Forms. Previamente ao preenchimento do formulário, os participantes tiveram que dar o seu consentimento informado, que os clarificava acerca do propósito da investigação e assegurava o cumprimento de questões éticas à investigação científica. Todos os participantes foram informados, 
por escrito, de que a sua participação era voluntária e anónima, existindo a possibilidade de desistência, se assim o desejassem. Constou também que os dados recolhidos eram completamente confidenciais e utilizados apenas para fins da presente investigação. O link para aceder ao formulário foi divulgado através das redes sociais e de contactos informais no primeiro semestre de 2021.

\subsubsection{Procedimento de análise de dados}

Os dados recolhidos foram analisados detalhadamente com recurso ao software Statistical Package for the Social Sciences - SPSS (versão 26.0) para Windows. Recorreu-se também à calculadora interativa de Preacher e Leonardelli (2001) para o cálculo do teste de Sobel e ao programa ModGraph-I (José, 2013) para a construção dos gráficos de moderação.

Numa primeira instância, efetuou-se a análise descritiva dos dados obtidos, através das medidas de tendência central e de dispersão, mais precisamente, a média e o desvio-padrão. Posteriormente, recorreu-se à análise de correlações (Coeficiente de Correlação de Pearson) entre as variáveis em estudo, com o intuído de analisar as associações entre os construtos. Realizou-se regressões lineares para estudar o valor preditivo das variáveis na ideação suicida. E, por último, efetuou-se análises de mediação e de moderação, recorrendo ao modelo de Baron e Kenny (1986), com o propósito de aprofundar o valor que as variáveis possuem nas relações existentes.

Para avaliar o efeito da mediação seguiram-se os seguintes procedimentos: (a) verificar a existência de correlação entre a variável independente e a variável dependente; (b) verificar se a variável independente está correlacionada significativamente a variável mediadora; (c) verificar se a variável mediadora afeta a relação existente entre a variável independente e dependente; (d) analisar se o efeito indireto da mediação é significativo; e (e) verificar se a mediação é total (a relação entre a variável independente e dependente deixa de ser significativa, na presença de uma terceira variável) ou parcial (a intensidade da relação entre a variável independente e dependente é atenuada, na presença de uma terceira variável mediadora).

Em relação à moderação: (a) centrar o preditor e o moderador; (b) criar uma nova variável representando a interação entre as duas variáveis (preditor e moderador); (c) realizar uma regressão múltipla por blocos, em que entram em primeiro lugar os preditores isolados e em segundo a nova variável, caso o contributo específico do $2^{\circ}$ bloco for significativo, então existe moderação; e (d) como deu significativo, calcular os declives e representar graficamente.

\section{Resultados}

\subsection{Análise Descritiva}

Apresentam-se, de seguida, as estatísticas descritivas - média e desvio-padrão - das variáveis estudadas (Tabela 1). 


\section{TABELA 1}

Estatísticas Descritivas da Ideação Suicida, Perfeccionismo, Depressão e Acontecimentos de Vida Negativos

\begin{tabular}{lcc}
\hline & M & DP \\
\hline IN (PANSI) & 1.53 & 0.98 \\
\hline IP (PANSI) & 3.67 & 0.72 \\
\hline PAO (HMPS) & 82.65 & 18.74 \\
\hline PSP (HMPS) & 45.87 & 13.91 \\
\hline EADS-21 & 25.13 & 16.57 \\
\hline D (EADS-21) & 7.65 & 6.20 \\
\hline CTQ-SF & 47.59 & 10.42 \\
\hline AE (CTQ-SF) & 9.00 & 4.58 \\
\hline NE (CTQ-SF) & 9.92 & 4.52 \\
\hline AS (CTQ-SF) & 5.93 & 2.86 \\
\hline AF (CTQ-SF) & 5.66 & 1.94 \\
\hline NF (CTQ-SF) & 6.39 & 2.17 \\
\hline
\end{tabular}

Nota. $M$ = Média; $D P$ = Desvio-Padrão; IN (PANSI) = Ideação Negativa; IP (PANSI) = Ideação Positiva; PAO (HMPS) = Perfeccionismo Auto-Orientado; PSP (HMPS) = Perfeccionismo Socialmente Prescrito; EADS-21 = Escala de Ansiedade, Depressão e Stresse; D (EADS-21) = Depressão; CTQ-SF = Questionário de Trauma de Infância - Versão Breve; AE (CTQ-SF) = Abuso Emocional; NE (CTQ-SF) = Negligência Emocional; AS (CTQ-SF) = Abuso Sexual; AF (CTQ-SF) = Abuso Físico; NF (CTQ-SF) = Negligência Física.

No que diz respeito à pontuação da amostra total na ideação negativa (amplitude de 1-5), pode-se observar valores abaixo do valor médio central da escala $(M=1.53$; $D P=0.98)$. Contrariamente, a ideação positiva encontra-se acima da pontuação central. Deste modo, é possível destacar que a ideação suicida nestes jovens-adultos, não é, globalmente, elevada.

Quanto às dimensões do perfeccionismo, o perfeccionismo auto-orientado evidencia um valor médio total relativamente elevado (amplitude de 18-126), enquanto que o perfeccionismo socialmente prescrito obteve um valor médio ligeiramente abaixo da pontuação central, tendo em consideração a amplitude de respostas possíveis (14-98 pontos). A depressão mostra um valor médio total relativamente baixo (amplitude de 0-21).

Em relação ao estudo dos acontecimentos de vida negativos, constatou-se que o valor médio é relativamente baixo, considerando a amplitude de cada escala total (entre 28 e 140) e de cada subescala (entre 5 e 25 pontos).

\subsection{Relação entre perfeccionismo, sintomatologia depressiva e acontecimentos de vida negativos}

De modo a compreender a relação entre os fatores de risco em estudo, nomeadamente entre as dimensões do perfeccionismo, a sintomatologia depressiva e os acontecimentos de vida negativos, recorreu-se ao coeficiente de correlação de Pearson (Tabela 2). 


\section{TABELA 2}

Correlações de Pearson (r) entre os Fatores de Risco

\begin{tabular}{lccc}
\hline & PAO (HMPS) & PSP (HMPS) & D (EADS-21) \\
\hline PSP (HMPS) & $.35^{\star \star *}$ & - & \\
D (EADS-21) & .06 & $.48^{\star \star *}$ & - \\
CTQ-SF & $.14^{\star}$ & $.44^{\star * *}$ & $.41^{\star \star *}$ \\
\hline
\end{tabular}

Nota. PAO (HMPS) = Perfeccionismo Auto-Orientado; PSP (HMPS) = Perfeccionismo Socialmente Prescrito; D (EADS-21) = Depressão; CTQ-SF = Questionário de Trauma de Infância - Versão Breve.

${ }^{*} p<.05 ;{ }^{* *} p<.01 ;{ }^{* *} p<.001$

O perfeccionismo auto-orientado apresenta uma correlação positiva, com significância estatística, mas negligenciável com os acontecimentos de vida negativos $(p=.031)$ e não se associa de forma significativa com a sintomatologia depressiva $(p=.416)$.

O perfeccionismo socialmente prescrito correlaciona-se de positiva, moderada e significativamente com a depressão $(p<.001)$ e com os acontecimentos de vida negativos $(p<.001)$.

De referir, ainda, que a depressão e os acontecimentos de vida negativos se encontram correlacionados de forma positiva, moderada e muito significativa $(p<.001)$, indicando que tendem a evoluir no mesmo sentido.

Torna-se possivel verificar que, na globalidade, os fatores de risco correlacionam-se de forma positiva entre si.

Prosseguindo com a análise das associações entre as variáveis, procurou-se, desta vez, conhecer a relação entre os fatores de risco considerados e a ideação suicida positiva e negativa (Tabela 3).

\section{TABELA 3}

Correlações de Pearson (r) entre os Fatores de Risco e a Ideação Suicida

\begin{tabular}{|c|c|c|}
\hline & IN (PANSI) & IP (PANSI) \\
\hline PAO (HMPS) & .04 & .05 \\
\hline PSP (HMPS) & $.41^{\star \star \star}$ & $-.47^{\star \star \star}$ \\
\hline EADS-21 & $.60^{\star \star \star}$ & $-.52^{\star \star \star}$ \\
\hline $\mathrm{D}(\mathrm{EADS}-21)$ & $.67^{\star \star *}$ & $-.62^{* * *}$ \\
\hline CTQ-SF & $.44^{\star * *}$ & $-.29 * \star \star$ \\
\hline AE (CTQ-SF) & $.35^{\star \star \star}$ & $-.32 * * *$ \\
\hline NE (CTQ-SF) & $.46^{\star \star \star}$ & $-.40 * \star \star$ \\
\hline AS (CTQ-SF) & $.38^{\star \star *}$ & $-.22^{* * *}$ \\
\hline AF (CTQ-SF) & $.14^{\star}$ & .00 \\
\hline NF (CTQ-SF) & $.34^{\star \star \star}$ & $-.16^{*}$ \\
\hline
\end{tabular}

Nota. IN (PANSI) = Ideação Negativa; IP (PANSI) = Ideação Positiva; PAO (HMPS) = Perfeccionismo Auto-Orientado; PSP (HMPS) = Perfeccionismo Socialmente Prescrito; EADS-21 = Escala de Ansiedade, Depressão e Stresse; D (EADS-21) = Depressão; CTQ-SF = Questionário de Trauma de Infância - Versão Breve; AE (CTQ-SF) = Abuso Emocional; NE (CTQ-SF) = Negligência Emocional; AS (CTQ-SF) = Abuso Sexual; AF (CTQ-SF) = Abuso Físico; NF (CTQ-SF) = Negligência Física.

${ }^{*} p<.05 ;{ }^{* *} p<.01 ;{ }^{* *} p<.001$ 
Os resultados da Tabela 3 mostram, tal como seria de esperar, que os fatores de risco se associaram de forma positiva com a ideação negativa.

Obteve-se uma correlação não significativa entre o perfeccionismo auto-orientado e ideação negativa $(p=.546)$. Relativamente ao perfeccionismo socialmente prescrito e a ideação negativa, verificou-se uma associação significativa, positiva e moderada $(p<.001)$. Estes resultados apontam que quanto maior os níveis de perfeccionismo socialmente prescrito, maior a tendência do jovem-adulto para pensamentos acerca de condutas suicidas.

A respeito da depressão apurou-se uma correlação significativa, positiva e forte com a ideação negativa $(p<.001)$. Tais resultados sugerem que, quanto maiores os níveis de sintomatologia depressiva experienciados pelo jovem-adulto, maior será a sua propensão para a ideação suicida.

No que se refere aos acontecimentos de vida negativos (CTQ-SF) e a ideação negativa, constatou-se uma associação significativa e positiva ao nível da escala total $(r=.44, p<.001)$ e das subescalas abuso emocional, abuso sexual, negligência física e negligência emocional. Os resultados obtidos apontam para que, quanto mais frequentes e quanto maior o impacto dos acontecimentos de vida negativos, maior será a tendência para pensamentos suicidas.

Os coeficientes de correlação de Pearson são globalmente negativos entre os fatores de risco e a ideação positiva.

O perfeccionismo auto-orientado e a subescala de abuso físico não se associam significativamente com a ideação positiva. As restantes variáveis apresentam uma correlação negativa e significativa e moderada com a ideação positiva.

De modo a estimar o contributo diferencial dos fatores de risco na explicação da ideação suicida, recorreu-se à técnica de regressão linear. Considerou-se, nesse âmbito, o perfeccionismo socialmente prescrito, a depressão e os acontecimentos de vida negativos como variáveis preditoras e a ideação negativa como variável dependente (Tabela 4).

\section{TABELA 4}

Contributo das Variáveis na Explicação da Ideação Suicida (IN - PANSI)

\begin{tabular}{lll}
\hline Ideação Suicida Negativa (IN - PANSI) & & \\
\hline PSP (HMPS) & $\beta=.055$ & \\
D (EADS-21) & $\beta=.563^{\star \star *}$ \\
CTQ-SF & $\beta=.185^{\star \star \star}$ & \\
\hline
\end{tabular}

Nota. ${ }^{*}=$ Valor significativo: = Coeficiente de Determinação; $\beta=$ Coeficiente de regressão padronizado; PAO (HMPS) $=$ Perfeccionismo Auto-Orientado; PSP (HMPS) = Perfeccionismo Socialmente Prescrito; D (EADS-21) = Depressão; CTQ-SF = Questionário de Trauma de Infância - Versão Breve.

${ }^{*} p<.05 ;{ }^{* *} p<.01 ;{ }^{* *} p<.001$

A análise dos resultados da Tabela 4 mostra que os fatores de risco expostos explicam $48 \%$ dos níveis de ideação suicida, sendo o contributo da depressão $(p<.001)$ e dos acontecimentos de vida negativos ( $p=.001)$ bastante significativos. O perfeccionismo socialmente prescrito $(p=.344)$ não contribuiu de forma significativa para o modelo de regressão. A sintomatologia depressiva apresentou o maior contributo constituindo-se como o melhor preditor da ideação suicida. 


\subsection{Relação entre os acontecimentos de vida negativos e a ideação suicida: o papel media- dor da sintomatologia depressiva}

No prosseguimento dos objetivos explorou-se se a relação entre os acontecimentos de vida negativos e a ideação suicida é apenas direta ou se mediada pela sintomatologia depressiva. Assim, consideraram-se os acontecimentos de vida negativos como variável independente; a ideação negativa como variável dependente e o eventual papel mediador da depressão (Figura 1).

Numa primeira instância, analisou-se a correlação entre a variável independente e a variável dependente, ou seja, se existe uma associação significativa entre os acontecimentos de vida negativos e a ideação suicida. Os resultados revelam um valor significativo $(\beta=.439, p<.001)$.

De seguida, averiguou-se se existia uma relação linear entre os acontecimentos de vida negativos e a depressão, onde foi possivvel confirmar a existência de um efeito significativo ( $\beta=.408$, $p<.001)$.

De modo a verificar se a sintomatologia depressiva afeta a relação entre os acontecimentos de vida negativos e a ideação suicida, realizou-se uma regressão múltipla, obtendo-se que o contributo da sintomatologia depressiva quando inclui também os acontecimentos de vida negativos para explicar a ideação suicida é significativo $(\beta=.583, p<.001)$. Esta regressão mostrou ainda que, apesar de o valor baixar (de $\beta=.439$ para $\beta=.201$ ), a associação entre os acontecimentos de vida negativos e a ideação suicida mantém-se significativa na presença do mediador ( $\beta=.201$, $p<.001)$, resultando numa mediação parcial.

Posteriormente, recorreu-se ao Teste de Sobel, com a finalidade de analisar a significância do efeito mediador, isto é, se a sintomatologia depressiva desempenha um papel mediador na relação entre os acontecimentos de vida negativos e a ideação suicida. Os resultados obtidos indicam que o efeito mediador (indireto) é significativo (Teste de Sobel $=5.82, p<.001$ ).

Por último, avaliou-se a percentagem da mediação parcial.

\section{FIGURA 1}

Modelo de Mediação relativamente ao efeito da depressão na relação entre os acontecimentos de viga negativos e a ideação suicida

$$
\beta=.201
$$

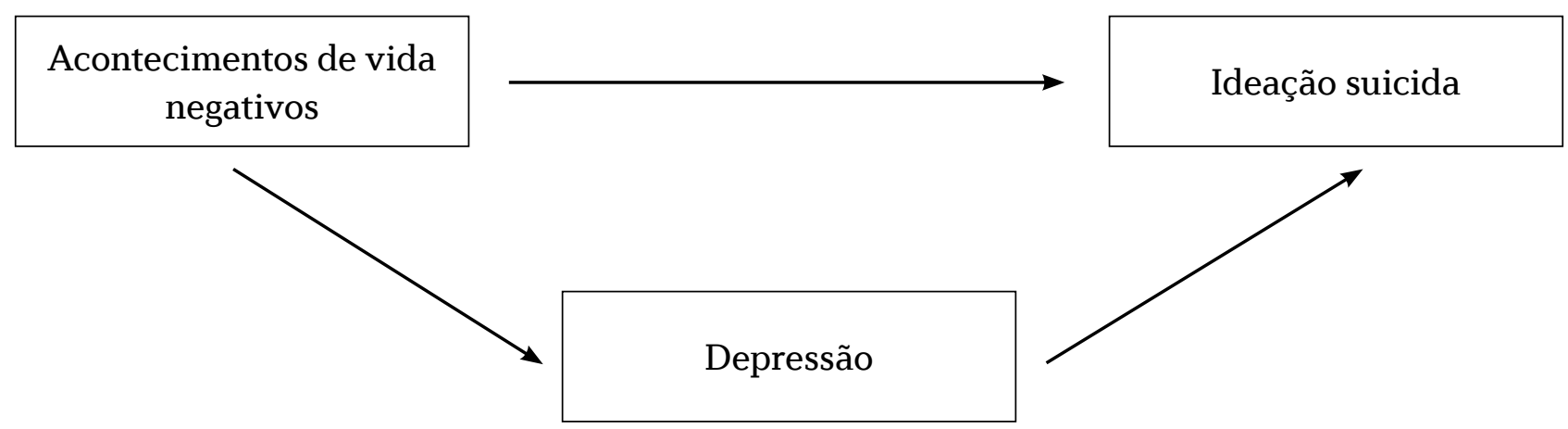


TABELA 5

Análise de Mediação: Acontecimentos de Vida Negativos - Depressão - Ideação Suicida (IN - PANSI)

\begin{tabular}{lcccc}
\hline Efeito em estudo & Efeito total & Efeito direto & Efeito indireto & Observações \\
\hline $\begin{array}{l}\mathrm{A} V \mathrm{~N} \rightarrow \mathrm{IN} \\
(\mathrm{D})\end{array}$ & $0.44^{* * *}$ & $0.20^{* * *}$ & $0.24^{\star * *}$ & Mediação Parcial \\
& & & $(54.21 \%)$ \\
\hline
\end{tabular}

Nota. * = Valor significativo; AVN = Acontecimentos de Vida Negativos; IN = Ideação Suicida Negativa; D = Depressão.

${ }^{*} p<.05 ;{ }^{* *} p<.01 ;{ }^{* *} p<.001$

A relação entre os acontecimentos de vida negativos e a ideação suicida (Tabela 5), não foi totalmente explicada pela variável independente, existindo o efeito de mediação parcial (54,21\%) da depressão.

\subsection{Relação entre a sintomatologia depressiva e a ideação suicida: o papel moderador das dimensões do perfeccionismo}

De acordo com a literatura, considerou-se relevante, analisar o papel moderador das dimensões do perfeccionismo na relação entre a sintomatologia depressiva e a ideação suicida. Constatou-se que o perfeccionismo auto-orientado não modera a relação entre a sintomatologia depressiva e a ideação suicida ( $=.002, p=.383$ ). Contudo, o perfeccionismo socialmente prescrito modera $(=.033, p<.001)$, sugerindo que a relação entre as variáveis é mais intensa em sujeitos com níveis mais elevados de perfeccionismo socialmente prescrito (Figura 2).

\section{FIGURA 2}

Gráfico do efeito da moderação da depressão na relação entre perfeccionismo socialmente prescrito e ideação suicida

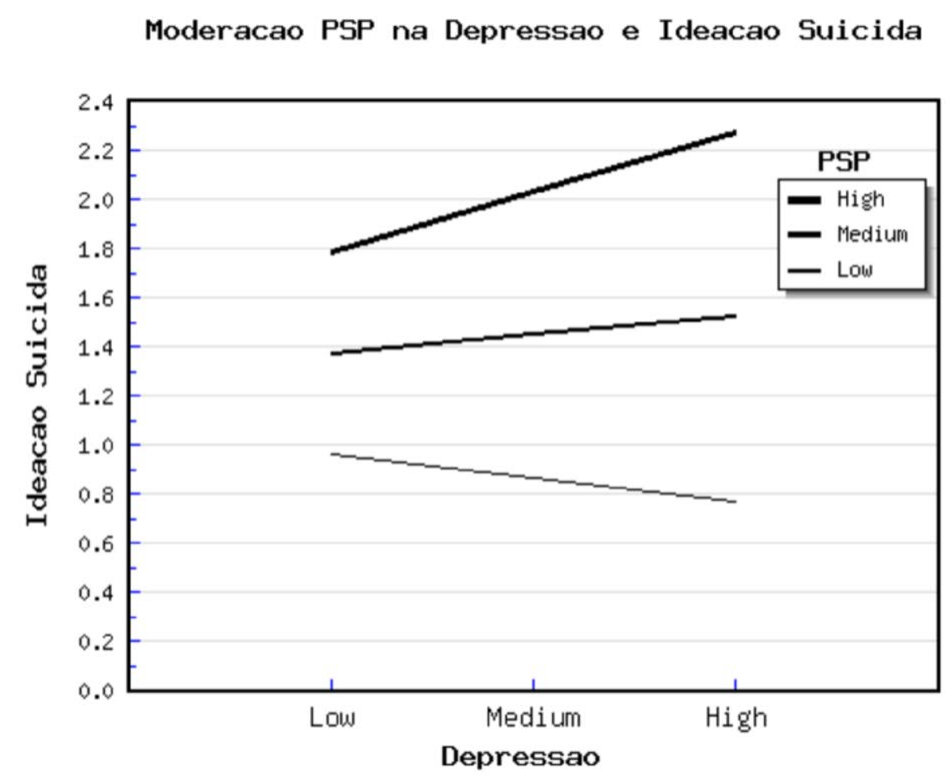




\section{Discussão}

A presente investigação teve como principal objetivo analisar a influência dos acontecimentos de vida negativos, das dimensões do perfeccionismo e da sintomatologia depressiva na ideação suicida, numa amostra de jovens-adultos de nacionalidade portuguesa. Acrescenta-se que, estudou-se a relação entre as variáveis, o papel das diferentes variáveis na explicação da ideação suicida e o modo como estas interagem com a ideação suicida.

É pertinente salientar que, ao longo do estudo, assumiu-se a ideação suicida (pensamentos e cognições sobre pôr fim à própria vida) como variável dependente, uma vez que é considerada o marco primário do processo suicidário. Representa um forte preditor para a ocorrência de comportamentos suicidários, o que significa que, quanto maior for os níveis de ideação suicida, maior será o risco para que o indivíduo cometa um comportamento suicida (DGS, 2013). Através dos resultados, foi possível verificar que quase metade dos jovens-adultos já sentiram que não valia apena viver (46.4\%). Deste modo, enaltece-se a necessidade de atribuir uma especial atenção a esta população, realçando que de facto é um resultado preocupante.

Tendo em consideração que o risco de suicídio não é apenas determinado pela ideação suicida, pretendeu-se explorar os niveis dos seguintes fatores de risco: perfeccionismo, acontecimentos de vida negativos e sintomatologia depressiva.

A análise dos valores médios das variáveis em estudo evidenciou que os jovens-adultos pontuaram tendencialmente baixo nas variáveis consideradas de risco para os atos suicidas, nomeadamente no perfeccionismo socialmente prescrito, na depressão, nos acontecimentos de vida negativos e na ideação suicida. O que vai ao encontro com o que seria esperado, considerando que se trata de uma amostra não-clínica. No mesmo sentido, estudos que têm comparado o risco de suicídio entre jovens da população não-clínica e jovens da população clínica com história de atos suicidas tendem a registar no primeiro grupo, valores de risco mais baixos (O'Connor, 2007).

$\mathrm{Na}$ análise correlacional entre os fatores de risco em estudo, os resultados evidenciaram que estes correlacionam-se de forma positiva e significativa.

Os acontecimentos de vida negativos apresentam uma associação significativa com ambas as dimensões do perfeccionismo (perfeccionismo auto-orientado e perfeccionismo socialmente prescrito), o que vai ao encontro do estudo de Chen et al. (2019) que revela que os abusos infantis são preditores do perfeccionismo auto-orientado e do perfeccionismo socialmente prescrito. Deduz-se, portanto, que jovens que registaram maior ocorrência de acontecimentos de vida negativos, tendem a apresentar também níveis mais elevados de perfeccionismo.

Os acontecimentos de vida negativos também se associaram significativamente à depressão. Pinto et al. (2015) enaltecem que a exposição a experiências adversas na infância é um preditor da sintomatologia depressiva. Chang et al. (2016) enfatizam ainda que a ocorrência de acontecimentos de vida negativos aumenta significativamente o surgimento de sintomatologia depressiva e comportamentos suicidas. Em conformidade com os resultados, destaca-se que quanto maior a vivência de acontecimentos de vida negativos, maior será a propensão para desenvolver sintomatologia depressiva.

Relativamente à relação entre a depressão e as duas dimensões do perfeccionismo, a sintomatologia depressiva apenas se associa ao perfeccionismo socialmente prescrito. Este resultado corrobora o estudo de Smith et al. (2018) que evidencia que o perfeccionismo socialmente prescrito confere vulnerabilidade aos indivíduos para desenvolverem sintomatologia depressiva. 
Contudo, acaba por refutar o estudo de Besser et al. (2010), visto que admitia que indivíduos com altos níveis de perfeccionismo auto-orientado também são propensos a desenvolver sintomatologia depressiva. Não obstante, Kiani e Khodabakhsh (2014) ressaltam a importância do perfeccionismo na predição da sintomatologia depressiva. Os resultados sugerem, desta forma, que quanto maior os níveis de perfeccionismo socialmente prescrito, maior será a tendência do jovem-adulto para desenvolver sintomatologia depressiva.

No prosseguimento da análise de resultados constatou-se que o perfeccionismo socialmente prescrito, os acontecimentos de vida negativos e a depressão se associam de forma positiva com a ideação suicida. Estes resultados corroboram estudos anteriores (e.g., Garlow et al., 2008; Liu \& Miller, 2014; May \& Klonsky, 2016; Roxboroug et al., 2012; Serafini et al., 2015; Smith et al., 2017; Ystgaard et al., 2004), sugerindo que tanto o perfeccionismo socialmente prescrito, os acontecimentos de vida negativos e a depressão poderão aumentar a vulnerabilidade para a ideação suicida.

Por outro lado, o perfeccionismo auto-orientado não se correlacionou com a ideação suicida, o que contraria o que se encontra exposto na literatura, que ambas as variáveis se encontram associadas (Robinson et al., 2021; Smith et al., 2017).

Procurou-se compreender o efeito das variáveis como potenciais fatores de risco nos níveis de ideação suicida enquanto variável dependente, à exceção do perfeccionismo auto-orientado, pois não apresentou uma correlação significativa com a ideação suicida. Quando se analisou o contributo diferencial destes fatores constatou-se que, em conjunto, explicam quase metade ( = .48) dos níveis de ideação suicida, sendo o contributo positivo e significativo. Embora se perspetive teoricamente que o perfeccionismo socialmente prescrito se associa positiva e significativamente com a ideação suicida, o seu contributo não foi significativo na presença dos outros já referidos.

Apurou-se, ainda, que a depressão é a variável com o maior valor preditor. Este resultado é altamente corroborado pela literatura, sendo que os indivíduos que apresentam ideação suicida manifestam sintomas depressivos significativamente mais graves (Garlow et al., 2008).

Dado o contributo dos acontecimentos de vida negativos e o seu estatuto de variável independente, pela sua própria natureza, procurou-se, compreender se o papel deste sobre a ideação suicida era, exclusivamente, direto ou mediado pela depressão.

Primeiramente, constatou-se que existe uma associação significativa entre os acontecimentos de vida negativos e os níveis de ideação suicida. Isto é, a ocorrência de acontecimentos de vida negativos, aumenta a vulnerabilidade do jovem-adulto para desenvolver pensamentos suicidas. Serafini et al. (2015) evidenciam que há uma relação robusta entre os acontecimentos de vida negativos e a ideação suicida.

Em seguida, averiguou-se se havia uma associação entre os acontecimentos de vida negativos e a sintomatologia depressiva, obtendo-se um valor significativo e positivo, concluindo que ambas tendem a evoluir no mesmo sentido. Chang et al. (2016) enfatizam que a existência de acontecimentos de vida negativos aumenta significativamente o surgimento de sintomatologia depressiva.

Por fim, obteve-se que existe uma mediação parcial da depressão, na relação entre os acontecimentos de vida negativos e a ideação suicida, corroborando com o estudo de Sobrinho e Campos (2016), que destaca o papel mediador da sintomatologia depressiva entre os acontecimentos de vida negativos e o risco de suicídio. É possível concluir que a presença de sintomatologia 
depressiva, juntamente com a exposição a acontecimentos de vida negativos, acentua os níveis de ideação suicida apresentados pelos jovens-adultos. Embora o contributo dos acontecimentos de vida negativos para a ideação suicida diminuía na presença da sintomatologia depressiva, continua a ser estatisticamente diferente de zero, o que significa que, além da relação mediada existe uma relação direta com a mesma.

Este resultado dá suporte ao Modelo Etiológico do Comportamento Suicida, desenvolvido por Yang e Clum, em 1996, uma vez que os autores postularam que existe uma associação entre os acontecimentos de vida negativos, os fatores cognitivos e o comportamento suicida. Segundo o modelo em questão, os acontecimentos de vida negativos podem conduzir ao desenvolvimento do comportamento suicida direta ou indiretamente.

Numa última instância, investigou-se o papel moderador das dimensões do perfeccionismo na relação entre a sintomatologia depressiva e a ideação suicida. Johnson et al. (2011) revelam que elevados níveis de perfeccionismo contribuem para amplificar outros fatores de risco que se encontram subjacentes ao comportamento suicidário.

Obteve-se que o perfeccionismo socialmente prescrito modera a relação entre a sintomatologia depressiva e a ideação suicida. Hewitt et al. (2014) enfatizam que o perfeccionismo socialmente prescrito é relevante na previsão do potencial suicida em adolescentes deprimidos. Finaliza-se que a relação entre a depressão e a ideação suicida é mais intensa em jovens-adultos com mais niveis de perfeccionismo socialmente prescrito.

Os jovens-adultos com perfeccionismo desadaptativo tendem a estabelecer expetativas muito elevadas, objetivando metas irrealistas, que por vezes, são incapazes de alcançar. Por consequente, pode ocorrer uma maior probabilidade de falhar, possibilitando a perceção de se sentirem um fracasso mais frequentemente, o que pode conduzir à ideação suicida. O perfeccionismo socialmente prescrito pode ainda aumentar a ideação suicida na presença de indivíduos que apresentem sintomatologia depressiva. Além do mais, os jovens-adultos que detêm esta dimensão do perfeccionismo poderão apresentar maior vulnerabilidade para o desenvolvimento de sintomatologia depressiva (Smith et al., 2018).

$\mathrm{Na}$ globalidade, os resultados foram ao encontro com o que estava estipulado na literatura, enaltecendo que o perfeccionismo, os acontecimentos de vida negativos e a sintomatologia depressiva são variáveis que conferem risco para o comportamento suicidário, sobretudo, para a ideação suicida.

\section{Conclusão}

O presente estudo possibilitou investigar as relações entre os diferentes fatores de risco para o comportamento suicidário, potencializando a compreensão de quais demonstram maior contributo para a ideação suicida e o modo como interagem. Ressalta-se que os elevados níveis de perfeccionismo, a vivência de acontecimentos de vida negativos e a presença de sintomatologia depressiva são fatores essenciais para a identificação e prevenção do comportamento suicida, devido a despoletarem elevados níveis de ideação suicida. No que concerne à relação entre os acontecimentos de vida negativos a ideação suicida, conclui-se que o efeito entre as variáveis é parcialmente mediado pela sintomatologia depressiva. Adicionalmente, a relação entre a sintomatologia depressiva e a ideação suicida é moderada pelo perfeccionismo socialmente prescrito. 
Apesar de se terem alcançados os objetivos delineados, podemos enunciar algumas limitações na presente investigação. A primeira limitação remete para a dimensão do protocolo de recolha de dados, devido à sua extensão, visto que incluiu diversos instrumentos, o que poderá ter contribuído para uma diminuição dos níveis de atenção, concentração e motivação por parte dos participantes, influenciando, de certo modo, a qualidade das suas respostas. A segunda limitação relaciona-se com o facto de a recolha de dados ter sido elaborada online, o que por si só, pode acarretar fatores externos mais difíceis de controlar. A terceira limitação fundamenta-se no facto de não ter sido possivel recolher uma amostra clínica, condicionando o conhecimento aprofundado acerca da temática. A quarta limitação aponta para a grande discrepância entre sexos, sendo que o número de participantes do sexo feminino é evidentemente superior ao do sexo masculino.

Não obstante, verifica-se que o estudo permitiu: caracterizar os níveis de ideação suicida na amostra de jovens-adultos e o grau de prevalência das outras variáveis; validar o estatuto dos fatores de risco para a ideação suicida; ter explorado o potencial preditor dos fatores de risco, permitindo destacar aqueles que apresentam mais proeminência; destacar o papel que a sintomatologia depressiva assume enquanto variável mediadora na relação entre os acontecimentos de vida negativos e, por último; salientar o efeito moderador do perfeccionismo socialmente prescrito na relação entre a sintomatologia depressiva e a ideação suicida.

A nível das implicações clínicas/práticas do estudo, considera-se de extrema importância que o jovens-adultos que sejam vítimas de acontecimentos de vida negativos, apresentem elevados níveis de perfeccionismo socialmente prescrito e que revelem sintomatologia depressiva, beneficiem de apoio e acompanhamento psicológico o mais precocemente possível, de modo a evitar que os fatores em questão desencadeiem elevados níveis de ideação suicida e, consequentemente, aumentar o risco do jovem-adulto cometer algum ato suicida. Neste sentido, em termos de intervenção psicológica, é necessário intervir em jovens que tenham sido expostos a acontecimentos de vida negativos, potenciando a diminuição da sintomatologia depressiva, uma vez que afeta parcialmente a relação entre as experiências adversas e os niveis de ideação suicida. Intervir também em jovens que apresentam traços e comportamentos perfeccionistas, sobretudo, se for a crença que os outros possuem padrões e expetativas irrealistas para si próprio, pois o perfeccionismo socialmente prescrito modera a relação entre a sintomatologia depressiva e a ideação suicida.

Quanto a sugestões para estudos futuros, sugere-se a continuação do estudo dos mesmos fatores e a inclusão de novos fatores, de modo a compreender os fatores que explicam os níveis de ideação suicida; investigar noutros potenciais papéis mediadores e moderadores; incluir uma amostra clínica, considerando a relevância da psicopatologia para a ideação suicida e para verificar se a interação entre as variáveis se mantém significativa; e, poderá ser pertinente recorrer a amostras equilibradas em relação ao número de participantes do sexo masculino e feminino, com a finalidade que seja possível generalizar os resultados.

Em suma, é de extrema importância continuar a investigar os fatores preditores associados ao processo suicidário, de modo a aumentar a prevenção do suicídio, diminuindo assim, a incidência do suicídio nesta faixa etária em Portugal. É relevante proporcionar acompanhamento psicológico especializado a jovens que tenham sido identificados com elevado nível de ideação suicida, de modo a reduzir a sintomatologia apresentada, com vista à redução do risco do jovem para cometer suicídio. 


\section{Referências}

American Psychiatric Association (2014). DMS-5: Manual de Diagnóstico e Estatística de Perturbações Mentais ( $5^{\mathrm{a}}$ edição). Climepsi Editores

Baron, R., \& Kenny, D. (1986). The Moderator-Mediator Variable Distinction in Social Psychological Research: Conceptual, Strategic, and Statistical Considerations. Journal of Personality and Social Psychology, 51(6), 1173-1182. https://doi.org/10.1037//0022-3514.51.6.1173

Bender, A. (2020). Perfectionism, Negative Life Events, and Cognitive Appraisal: A Contextual Model of Perfectionism's Maladaptive Nature [Master's thesis, University of South Florida]. Scholar Commons Citation. https://scholarcommons.usf.edu/etd/8008

Bernstein, D., Stein, J., Newcomb, M., Walker, E., Pogge, D., Ahluvalia, T., Stokes, J., Handelsman, L., Medrano, M., Desmond, D., \& Zule, W. (2003). Development and validation of a brief screening version of the Childhood Trauma Questionnaire. Child Abuse \& Neglect, 27(2), 169-190. https://doi. org/10.1016/S0145-2134(02)00541-0

Besser, A., Flett, G., \& Hewitt, P. (2010). Perfectionistic Self-Presentation and Trait Perfectionism in Social Problem-Solving Ability and Depressive Symptoms. Journal of Applied Social Psychology, 40(8), 21212154. https://doi.org/10.1111 / j.1559-1816.2010.00653.x

Botega, N., Barros, M., Oliveira, H., Dalgalarrondo, P., \& Marín-Léon, L. (2005). Suicidal behavior in the community: Prevalence and factors associated with suicidal ideation. Revista Brasileira de Psiquiatria, 27(1), 45-53. https://doi.org/10.1590/s1516-44462005000100011

Brennan-Wydra, E., Chung, H., Angoff, N., ChenFeng, J., Phillips, A., Schreiber, J., Young, C., \& Wilkins, K. (2021). Maladaptive Perfectionism, Impostor Phenomenon, and Suicidal Ideation Among Medical Students. Academic Psychiatry, 45, 708-715. https://doi.org/10.1007/s40596-021-01503-1

Chang, E., Yu, E., Yu, T., Kahle, E., Hernandez, V., Kim, J., Jeglic, E., \& Hirsch, J. (2016). Ethnic Variables and Negative Life Events as Predictors of Depressive Symptoms and Suicidal Behaviors in Latino College Students: On the Centrality of Receptivo a los Demás. Hispanic Journal of Behavioral Sciences 38(2) 206-221. https://doi.org/10.1177/0739986316641418

Chen, C., Hewitt, P., \& Flett, G. (2019). Adverse childhood experiences and multidimensional perfectionism in young adults. Personality and Individual Differences, 146, 53-57. https://doi.org/10.1016/j. paid.2019.03.042

Dias, A., Sales, L., Carvalho, A., Castro-Vale, I., Kleber, R., \& Cardoso, R. (2013). Estudo de propriedades psicométricas do Questionário de Trauma de Infância - Versão breve numa amostra portuguesa não clínica. Laboratório de Psicologia, 11(2), 103-120. https://doi.org/10.14417/lp.11.2.713

Direção-Geral da Saúde. (2013) Plano Nacional de Prevenção do Suicídio (2013/2017). https://www.dgs.pt/ documentos-e-publicacoes/plano-nacional-de-prevencao-do-suicido-20132017.aspx

Falgares, G., Marchetti, D., Manna, G., Musso, P., Oasi, O., Kopala-Sibley, D., Santis, S., \& Verrocchio, M. (2018). Childhood Maltreatment, Pathological Personality Dimensions, and Suicide Risk in Young Adults. Frontiers in Psychology, 9(806). https://doi.org/10.3389/fpsyg.2018.00806

Fonte, C., Ferreira, C., \& Alves, S. (2017). Estudo da saúde mental positiva em jovens adultos: relações entre psicopatologia e bem-estar. Psique, 13, 57-74

Frost, R., Marten, P., Lahart, C., \& Rosenblate, R. (1990). The dimensions of perfectionism. Cognitive Therapy and Research, 14(5), 449-468. https://doi.org/10.1007/BF01172967

Garlow, S. J., Rosenberg, J., Moore, J. D., Haas, A. P., Koestner, B., Hendin, H., \& Nemeroff, C. B. (2008). Depression, desperation, and suicidal ideation in college students: results from the American 
Foundation for Suicide Prevention College Screening Project at Emory University. Depression and Anxiety, 25(6), 482-488. https://doi.org/10.1002/da.20321

Hewitt, P. L., \& Flett, G. L. (1991). Perfectionism in the self and social contexts: Conceptualization, assessment, and association with psychopathology. Journal of Personality and Social Psychology, 60(3), 456470. https://doi.org/10.1037/0022-3514.60.3.456

Hewitt, P. L., Flett, G. L., \& Mikail, S. F. (2017). Perfectionism: A relational approach to conceptualization, assessment, and treatment. The Guilford Press

Hewitt, P. L., Flett, G. L., Sherry, S. B., \& Caelian, C. (2006). Trait perfectionism dimensions and suicidal behavior. In T. E. Ellis (Ed.), Cognition and suicide: Theory, research, and therapy (pp. 215-235). American Psychological Association

Hewitt, P., Caelian, C., Chen, C., \& Flett, G. (2014). Perfectionism, stress, daily hassles, hopelessness, and suicide potential in depressed psychiatric adolescents. J. Psychopathol Behav Assess, 36, 663-674. https://doi.org/10.1007/510862-014-9427-0

Instituto Nacional de Estatística. (2021). Portal do Instituto Nacional de Estatística. https://www.ine.pt/ xportal/xmain?xpid=INE\&xpgid=ine_indicadores\&indOcorrCod=0003736\& contexto=bd\&selTab=tab2

Johnson, J., Wood, A. M., Gooding, P., Taylor, P. J., \& Tarrier, N. (2011). Resilience to suicidality: The buffering hypothesis. Clinical Psychology Review, 31, 563-591. https://doi.org/10.1016/j.cpr.2010.12.007

Jonge-Heesen, K., Rasing, S., Vermulst, A., Engels, R., \& Creemers, D. (2021). How to Cope with Perfectionism? Perfectionism as a Risk Factor for Suicidality and the Role of Cognitive Coping in Adolescents. Journal of Rational-Emotive \& Cognitive-Behavior Therapy, 39, 201-216. https://doi.org/10.1007/s10942020-00368-x

Jose, P. (2013). ModGraph-I: A programme to compute cell means for the graphical display of moderational analyses: The internet version. https://psychology.victoria.ac.nz/modgraph/

Kiani, F., \& Khodabakhsh, M. (2014). Perfectionism and Stressful Life Events as Vulnerabilities to Depression Symptoms in Students. International Journal of Pediatrics, 2(4), 277-285. https://doi.org/10.22038/ ijp.2014.3244

Liu, J., Fang, Y., Gong, J., Cui, X., Meng, T., Xiao, B., He, Y., Shen, Y., \& Luo, X. (2017). Associations between suicidal behavior and childhood abuse and neglect: A meta-analysis. Journal of Affective Disorders, 220, 147-155. http://dx.doi.org/10.1016/j.jad.2017.03.060

Liu, R., \& Miller, I. (2014). Life events and suicidal ideation and behavior: A systematic review. Clinical Psychology Review, 34, 181-192. http://dx.doi.org/10.1016/j.cpr.2014.01.006

Lovibond, P., \& Lovibond, S. (1995). The structure of negative emotional states: Comparison of the depression anxiety stress scales (DASS) with the Beck Depression and Anxiety Inventories. Behaviour Research and Therapy, 33(3), 335-343. https://doi.org/10.1016/0005-7967(94)00075-U

Low, Y., Kwok, S., Tam, H., Yeung, W., \& Lo, H. (2017). The relationship between childhood physical abuse and suicidal ideation among Chinese university students: Possible moderators. Children and Youth Services Review, 81, 94-100. http://dx.doi.org/10.1016/j.childyouth.2017.07.026

May, A., \& Klonsky, E. (2016). What distinguishes suicide attempters from suicide ideators? A meta-analysis of potential factors. Clinical Psychology: Science and Practice, 23, 5-20. https://doi.org/10.1111/ cpsp.12136

Muehlenkamp, J., Gutierrez, P., Osman, A., \& Barrios, F. (2005). Validation of the Positive and Negative Suicide Ideation (PANSI) Inventory in a Diverse Sample of Young Adults. Journal of Clinical Psychology, 61(4), 431-445. https://doi.org/10.1002/jclp.20051 
O'Connor, R. (2007). The relations between perfectionism and suicidality: a systematic review. Suicide and life-threatening behavior, 37(6), 698-714. https://doi.org/10.1521/suli.2007.37.6.698 https://doi.org/10.1016/j.brat.2009.09.008

Organização Mundial da Saúde. (2021). Suicide worldwide in 2019: Global Health Estimates. https://www. who.int/publications/i/item/9789240026643

Osman, A., Gutierrez, P. M., Kopper, B. A., Barrios, F. X., \& Chiros, C. E. (1998). The positive and negative suicide ideation inventory: Development and validation. Psychological Reports, 82(3), 783-793. https://doi.org/10.2466/pr0.1998.82.3.783

Pais-Ribeiro, J. L., Honrado, A., \& Leal, I. (2004). Contribuição para o estudo da adaptação portuguesa das escalas de ansiedade, depressão e stress (EADS) de 21 itens de Lovinbond e Lovinbond. Psicologia, Saúde \& Doenças, 5(2), 229-239.

Pinto, V., Alves, J., \& Maia, A. (2015). Adversidade na infância prediz sintomas depressivos e tentativas de suicídio em mulheres adultas portuguesas. Estudos de Psicologia, 32(4), 617-625. http://doi. org/10.1590/0103-166X2015000400005

Preacher, K., \& Leonardelli, G. (2001). Calculation for the Sobel test: An interactive calculation tool for mediation tests. http://quantpsy.org/sobel/sobel.htm

Rasmussen, K., Slish, M., Wingate, L., Davidson, C., \& Grand, D. (2012). Can perceived burdensomeness explain the relationship between suicide and perfectionism? Suicide and life-threatening behaviour, 42(2), 121-128. https://doi.org/10.1111/j.1943-278x.2011.00074.X

Robinson, A., Moscardini, E., Tucker, R., \& Calamia, M. (2021). Perfectionistic Self-Presentation, Socially Prescribed Perfectionism, Self-Oriented Perfectionism, Interpersonal Hopelessness, and Suicidal Ideation in U.S. Adults: Reexamining the Social Disconnection Model. Archives of Suicide Research. https://doi.org/10.1080/13811118.2021.1922108

Roxborough, H., Hewitt, P., Kaldas, J., Flett, G, Caelian, C., Sherry, S., \& Sherry, D. (2012). Perfectionistic self-presentation, socially prescribed perfectionism, and suicide in youth: A test of the perfectionism social disconnection model. Suicide and lifethreatening behaviour, 42(2), 217-233. https://doi. org/10.1111/j.1943-278X.2012.00084.x

Serafini, G., Muzio, C., Piccinini, G., Flouri, E., Ferrigno, G., Pompili, M., Girardi, P., \& Amore, M. (2015). Life adversities and suicidal behavior in young individuals:a systematic review. European Child $\delta$ Adolescent Psychiatry, 24, 1423-1446. https://doi.org/10.1007/s00787-015-0760-y

Shahnaz, A., Saffer, B. Y., \& Klonsky, E. D. (2018). The relationship of perfectionism to suicide ideation and attempts in a large online sample. Personality and Individual Differences, 130, 117-121. https://doi. org/10.1016/j.paid.2018.04.002

Smith, E. P., Hill, A. P., \& Hall, H. K. (2018). Perfectionism, Burnout, and Depression in Youth Soccer Players: A Longitudinal Study. Journal of Clinical Sport Psychology, 12(2), 179-200. https://doi.org/10.1123/ jcsp.2017-0015

Smith, M., Sherry, S., Chen, S., Saklofske, D., Mushquash, C., Flett, G., \& Hewitt, P. (2017). The perniciousness of perfectionism: a meta-analytic review of the perfectionism-suicide relationship. Journal of Personality, 86(3), 522-542. https://doi.org/10.1111/jopy.12333

Soares, M., Gomes, A., Macedo, A., \& Azevedo, M. (2003). Escala Multidimensional De Perfecionismo: Adaptação À População Portuguesa. Revista Portuguesa de Psicossomática, 5(1), 46-55

Sobrinho, A. T., \& Campos, R. C. (2016). Perceção de acontecimentos de vida negativos, depressão e risco de suicídio em jovens adultos. Análise Psicologica, 34(1), 47-60. https://doi.org/10.14417/ap.1061 
Sommerfeld, E., \& Malek, S. (2019). Perfectionism Moderates the Relationship between Thwarted Belongingness and Perceived Burdensomeness and Suicide Ideation in Adolescents. Psychiatric Quarterly, 90, 671-681. https://doi.org/10.1007/s11126-019-09639-y

Wang, Y., Sun, J., Lin, P., Zhang, H., Mu, G., \& Cao, F. (2019). Suicidality among young adults: Unique and cumulative roles of 14 different adverse childhood experiences. Child Abuse \& Neglect, 98. https://doi. org/10.1016/j.chiabu.2019.104183

Wenzel, A., \& Beck, A. T. (2008). A cognitive model of suicidal behavior : Theory and treatment. Applied and Preventive Psychology, 12, 189-201. https://doi.org/10.1016/j.appsy.2008.05.001

Yang, B., \& Clum, G. A. (1996). Effects of Early Negative Life Experiences on Cognitive Functioning and Risk for Suicide: A Review. Clinical Psychology Review, 16(3), 177-195. https://doi.org/10.1016/S02727358(96)00004-9

Ystgaard, M., Hestetun, I., Loeb, M., \& Mehlum, L. (2004). Is there a specific relationship between childhood sexual and physical abuse and repeated suicidal behavior? Child Abuse \& Neglect, 28, 863-875. https:// doi.org/10.1016/j.chiabu.2004.01.00

Zeifman, R., Antony, M., \& Kuo, J. (2020). When being imperfect just won't do: Exploring the relationship between perfectionism, emotion dysregulation, and suicidal ideation. Personality and Individual Differences, 152. https://doi.org/10.1016/j.paid.2019.109612 